\title{
A utilização de corpus na prática lexicográfica
}

\author{
Carolina Medeiros Coelho* \\ Fernanda Alvarenga Rezende ${ }^{\circ}$
}

RESUMO: Com este trabalho, temos o objetivo de investigar os verbos agarrar, apanhar, catar, pegar e tomar mostrando, com base nos dados extraídos do Corpus do Português, que eles podem ocorrer em um mesmo contexto codificando a ação de tomar posse de um objeto para si. Além disso, buscamos identificar uma acepção específica para cada um desses verbos, o que explica sua ocorrência em contextos mais particulares, também ilustrados com dados coletados do corpus, nos quais a ocorrência dos demais parece ser bloqueada. Fazemos, ainda, uma breve apresentação da lexicografia brasileira; do dicionário Aurélio, que foi escolhido como suporte para a nossa análise; do léxico e da sinonímia.

PALAVRAS-CHAVE: Lexicografia; dicionário Aurélio; verbos; corpora.

\begin{abstract}
With this paper, we aim to investigate the verbs agarrar, apanhar, catar, pegar and tomar showing that, based on data extracted from the Corpus of Portuguese, they can occur in the same context encoding the action of to take possession of an object to itself. Furthermore, we tried to identify a specific sense for each of these verbs, which explain their occurrence in more particular contexts, also illustrated with data collected from the corpus, in which the occurrence of the others seems to be blocked. We also give a brief presentation of the Brazilian lexicography; of the Aurélio dictionary, which was chosen as support for our analysis; of the lexicon and of the synonymy.
\end{abstract}

KEY-WORDS: Lexicography; the Aurélio dictionary; verbs; corpora.

\section{INTRODUÇÃO}

A Lexicografia brasileira sofreu transformações significativas desde as primeiras publicações na área. O século XX ficou marcado historicamente, pois, de acordo com Nunes (2010), nesse período foram publicados os primeiros grandes dicionários monolíngues. Com a consolidação da Lexicografia no Brasil nos anos 1900, o que se observa desde então é que a forma pela qual os dicionários brasileiros são elaborados vem sofrendo mudanças frequentes.

\footnotetext{
* Mestranda do PPGEL/UFU.

Mestranda do PPGEL/UFU.
} 
Além da tendência de transferir as obras publicadas em papel para a mídia eletrônica, observa-se a utilização de corpora linguísticos no fazer lexicográfico. Ainda tímida, essa nova proposta permite que os profissionais da área produzam obras com informações atualizadas dos verbetes, pautadas em dados sincrônicos da língua. Como referência no Brasil há o Dicionário de Usos do Português do Brasil (DUP), elaborado por Francisco Borba e publicado no ano de 2002. O DUP foi elaborado com base em um corpus constituído por mais de 70 milhões de palavras de textos diversos do século XX. Obras como essa, baseadas em dados reais da língua, são importantes na medida em que registram muitas palavras e até mesmo acepções que ainda não foram dicionarizadas por exemplo.

A fim de reforçar a importância de se utilizar corpus em trabalhos lexicográficos, apresentamos, neste artigo, uma análise dos verbos agarrar, apanhar, catar, pegar e tomar mostrando, com base nos dados retirados do Corpus do Português $^{1}$, seus contextos de uso. O Corpus do Português, organizado por Mark Davies e Michael Ferreira, é constituído por mais de 45 milhões de palavras, distribuídas em quase 57 mil textos do português divididos em orais, ficcionais, jornalísticos e acadêmicos. Devido a sua representatividade, será utilizado neste trabalho.

O interesse por investigar os verbos agarrar, apanhar, catar, pegar e tomar sob o ponto de vista da lexicografia surgiu por percebermos que, embora eles sejam semanticamente próximos, também podem ocorrer em contextos específicos, nos quais têm sentidos bem particulares e, por isso, a ocorrência de qualquer outro verbo parece ser bloqueada.

Tendo isso em vista, os objetivos deste trabalho são os seguintes:

$\rightarrow$ verificar, com base no Dicionário Aurélio da Língua Portuguesa $(2010)^{2}$, de Aurélio Buarque de Holanda Ferreira, se os verbos agarrar, apanhar, catar, pegar e tomar têm uma acepção em comum;

\footnotetext{
${ }^{1}$ O Corpus do Português se encontra disponível online para uso público em www.corpusdoportugues.org

2 Doravante, nos referiremos ao Dicionário Aurélio da Língua Portuguesa (2010) apenas por Aurélio (2010).
} 
$\rightarrow$ identificar, também a partir do Aurélio (2010), uma acepção particular de cada verbo que justifique seus usos em contextos bem específicos, nos quais a substituição por qualquer outro verbo parece não ser possível;

$\rightarrow$ comprovar empiricamente, a partir dos dados coletados do Corpus do Português, os contextos específicos de cada verbo e aquele que é comum a todos.

A escolha pelo Aurélio (2010) se deu pela relevância da obra no Brasil, pois é um dicionário muito utilizado em escolas, cursos, universidades, empresas, escritórios e lares, conforme descrito no próprio prefácio da obra.

Em consonância com os objetivos traçados, este artigo foi dividido da seguinte forma: primeiramente, na seção 2, faremos uma breve apresentação da lexicografia brasileira; do léxico e do Aurélio (2010), dicionário utilizado na nossa pesquisa. Em seguida, discorreremos sobre a escolha dos verbos que serão analisados neste artigo e sobre a questão da sinonímia. Na seção 4, trataremos da metodologia e do corpus que utilizamos. Por fim, na seção 5, faremos a análise desse corpus e, posteriormente, apresentaremos a conclusão.

\section{A LEXICOGRAFIA BRASILEIRA}

A colonização portuguesa trouxe para o Brasil, além da influência religiosa, a imposição de uma língua, que mais tarde foi consagrada a língua nacional do país. Salvas as implicações que a colonização teve na história do Brasil, discutiremos, especialmente, aquela que diz respeito à constituição do léxico do português brasileiro.

Segundo Nunes (2010, p. 09): “Os primeiros saberes lexicográficos produzidos no Brasil" foram, basicamente, listas de palavras Português-Tupi e Tupi-Português, das quais surgiram os primeiros dicionários bilíngues dessas línguas, elaborados pelos jesuítas com o objetivo de catequizar os índios.

Dentre os dicionários mais antigos têm-se o de Rafael Bluteau, intitulado Vocabulario Portuguez e Latino, publicado no século XVIII. Sobre essa obra, Biderman (1984, p. 04) afirma que: "Trata-se de um dicionário bilíngue português-latim que contém muita informação e bastante variada sobre essas duas línguas." Aos oito 
volumes do dicionário somaram-se dois suplementos com mais de cinco mil novos vocábulos ${ }^{3}$.

Essa obra serviu de inspiração ao brasileiro Antonio de Morais Silva, que publicou, em 1789, o Dicionário da Língua Portuguesa. Por ter se baseado em Bluteau, Morais Silva atribuiu a autoria da primeira edição do seu dicionário a ele; além disso, esclareceu que seu papel, nessa edição, foi a de reformar e acrescentar informações.

Na segunda edição, publicada em 1813, entretanto, Morais Silva assume a autoria da obra que é, segundo Biderman (1984, p. 05): “um marco na lexicografia de língua portuguesa", pois foi "o primeiro dicionário de uso da língua, muito avançado para os padrões lexicográficos da época." Com um trabalho lexicográfico mais apurado, Biderman (1984, p. 05) explica que Morais Silva “omitiu informações de tipo enciclopédico incluídas no Bluteau, revelando consciência de que um dicionário d[e] língua não é uma enciclopédia." Ademais, conforme Biderman (1984, p. 05), o autor lançou mão de abonações retiradas dos "melhores escritores dos séculos XVI e XVII." e se mostrou preocupado em acrescentar outros tipos de autores que não fossem apenas os literários. Por isso, encontram-se no dicionário obras de diferentes áreas do conhecimento (med., quim., astron., etc.), cujas indicações encontram-se após cada verbete.

Ainda no século XIX, segundo Nunes (2010, p. 10), surgem os dicionários de regionalismos, de brasileirismos e os dicionários que têm como fim complementar as obras portuguesas. A quantidade de dicionários produzidos nesse século já apontava para a consolidação da Lexicografia brasileira; entretanto, de acordo com Müller et al. (2009, p. 1426):

[f]oi no século XX que se inaugura a lexicografia brasileira seja porque surgem as primeiras edições de dicionários publicados no país, seja porque as obras pioneiras passam a registrar formalmente o léxico do $\mathrm{PB}$, permitindo a constituição identitária desse léxico. (Müller et al., 2009, p. 1426)

${ }^{3}$ O Vocabulario Portuguez e Latino, de Rafael Bluteau, e o Dicionário da Língua Portuguesa, de Antonio de Morais Silva, estão disponibilizados online em http://www.ieb.usp.br/online/index.asp. A digitalização das obras foi realizada por alunos e professores do Instituto de Estudos Brasileiros da Universidade de São Paulo (USP). 
Nunes (2010, p. 10) cita como expoentes desse período o Pequeno Dicionário Brasileiro da Língua Portuguesa e o Grande e Novíssimo Dicionário da Língua Portuguesa, elaborados por Gustavo Barroso e Hildebrando Lima; e Laudelino Freire, respectivamente. Além desses, Krieger et al. (2006, p 176) apontam como referências do século XX o Dicionário da Língua Portuguesa, de Antenor Nascentes, e o Novo Dicionário da Língua Portuguesa, de Aurélio Buarque de Holanda Ferreira. Esses são, portanto, os primeiros grandes dicionários monolíngues e, devido à abrangência de registros lexicais que apresentam, são considerados dicionários de língua, pois, conseguem explicitar "a história de fixação do léxico no Brasil", conforme afirmam Krieger et al. (2006, p. 177).

$[\mathrm{O}] \mathrm{s}$ primeiros dicionários que, por diferentes razões e interesses, passam a contemplar a realidade linguística no Brasil, desempenharam também o papel de fixar a unidade e a pluralidade do português aqui falado. (Krieger et al., 2006, p. 174)

Após esse período de consolidação, o que temos visto no trabalho lexicográfico do século XXI é a reinvenção dos dicionários tradicionais. Disponibilizados em versão eletrônica, os novos dicionários garantem uma maior interação com os consulentes, como o dicionário Aulete, que está disponível online desde 2007 e oferece acesso gratuito e ilimitado aos verbetes ${ }^{4}$.

Dicionários como o Aulete são frequentemente atualizados, seja pelos seus editores, seja pela colaboração de seus usuários, que podem sugerir novos verbetes ou acrescentar novos significados e informações (gramaticais, exemplos, pronúncia sonora, ilustrações, etc.) ao que já está disponível.

Além da transferência das versões originais publicadas em papel para a mídia eletrônica, os lexicógrafos, ao elaborar dicionários padrões de língua ou até mesmo os mais específicos, como os de sinônimos, os terminológicos, etc., têm utilizado $\operatorname{corpus}^{5}$ a

\footnotetext{
4 A versão online do dicionário Caldas Aulete está disponível no seguinte endereço eletrônico: http://aulete.uol.com.br/site.php?mdl=aulete digital.

${ }^{5}$ De acordo com Fromm (2003), corpus é “[...] uma coleção de textos reunidos, de áreas variadas ou não, com um propósito específico de análise." Acrescentamos ainda que esse conjunto de textos deve seguir uma sistematização com critérios específicos.
} 
fim de facilitar e enriquecer o trabalho lexicográfico. Ao contrário do que se imagina, a utilização de corpus na análise linguística não é uma atividade recente.

\begin{abstract}
A partir da metade do século XVIII [...] os lexicógrafos começaram a usar um 'corpus'. Naquela época, isso significava uma coleção de textos autênticos, dos quais eles extraiam, até certo ponto, sua palavraentrada e também, embora de maneira menos direta, a informação microestrutural. (Béjoint, 2000, p. 97 apud Welker, 2005, p. 88)
\end{abstract}

No passado, de acordo com Béjoint (2000, p. 97 apud Welker, 2005, p. 88): “os textos [...] não constituíam um corpus como o entendemos hoje", visto que os lexicógrafos adequavam o corpus de modo que ele atendesse as suas necessidades, sendo utilizado, principalmente, para confirmar suas intuições. A novidade da utilização de corpora na Lexicografia atual é que: “[...] todos os lexemas da nomenclatura, todos os seus significados e todas as citações que os ilustram vêm exclusivamente de um corpus" (Béjoint, 2000, p. 97 apud Welker, 2005, p. 88).

A maioria dos dicionários baseados em corpora constitui a Lexicografia internacional, como a primeira edição do Collins Cobuild, o dicionário italiano-alemão de verbos de Blumenthal \& Rovere, o Brown Corpus, o British National Corpus e o Bank of English. Para Welker (2005, p. 90), como referência no Brasil há o DUP, publicado em 2002.

Em vista disso, elucidamos a importância e a necessidade de expandir o uso de corpus na prática lexicográfica brasileira. A utilização de corpus promove aos dicionários uma proximidade maior com as mudanças que ocorrem na língua, uma vez que, por meio dele, o dicionarista tem acesso a palavras e acepções frequentemente utilizadas pelos falantes, mas que ainda não se encontram dicionarizadas.

O uso do corpus pode tornar o conteúdo dos dicionários mais interessante e mais rico para os consulentes, uma vez que esse conteúdo se aproximaria mais da língua tal como utilizada pelos seus falantes.

\title{
2.1. O léxico
}

O léxico de uma língua pode ser comparado com a construção de um prédio, em que a cada dia novos tijolos (palavras) são incorporados à base (língua) até que a obra 
seja concluída. Entretanto, ao contrário do prédio, a construção do léxico de uma língua não é finita, pois a língua está sempre em mudança. Essa mudança é lenta e gradual e, conforme Biderman (1984, p. 17):

O léxico constitui um conjunto aberto em qualquer sistema linguístico e, por conseguinte, não apenas vastíssimo quando comparado com outros setores e níveis da língua (fonológico, morfológico, sintático), mas também em permanente expansão, sobretudo numa língua de civilização.

Novas palavras são incorporadas à língua todos os dias e mesmo as palavras que já fazem parte do nosso léxico podem adquirir novas significações com o passar do tempo. Além disso, uma palavra pode ser usada em um mesmo contexto que outras, apresentando um mesmo sentido. Como exemplo disso, temos os cinco verbos agarrar, apanhar, catar, pegar e tomar - que escolhemos para analisar, uma vez que todos eles podem ser utilizados para exprimir a ação de tomar posse de um objeto para si.

Conforme Biderman $(1998)^{6}$, o léxico é o conjunto de palavras de uma língua e os dicionários são os responsáveis por registrar essa vasta quantidade de palavras. Além disso, o léxico é constituído por todos os signos linguísticos, por meio dos quais nos expressamos e adquirimos conhecimento.

Entretanto, sabe-se que por mais completo que se pretenda ser, nenhum trabalho lexicográfico, nem mesmo os dicionários gerais de língua, consegue cobrir todo o léxico de uma língua. Por isso, em meio a essa questão, discorreremos brevemente, a seguir, sobre o Dicionário Aurélio (2010), que já em sua primeira versão, de 1975, foi considerado um dicionário padrão da língua segundo Biderman (1984).

\subsection{O Dicionário Aurélio da Língua Portuguesa, de Aurélio Buarque de Holanda Ferreira}

A importância dessa obra incita o interesse em estudá-la e tomá-la como fonte de informação e estudo, especialmente, na área da Lexicografia. O Aurélio (2010),

6 Esse texto, intitulado Dicionário e léxico do Português Brasileiro, encontra-se disponível em: http://www.ime.usp.br/ is/educar2002/dicionarios/dicionarios.html, acesso em 20 de janeiro de 2012. 
portanto, constitui um dos suportes para a análise das acepções dos verbos agarrar, apanhar, catar, pegar e tomar, investigados nessa pesquisa.

Sua primeira versão, que chegou ao público em $1975^{7}$, é considerada, segundo Krieger et al. (2006), um tipo de thesaurus devido à extensão de sua nomenclatura, que atingiu quase 150 mil entradas. Duas edições após a inicial, de acordo com os autores, o dicionário já apresentava 435 mil verbetes.

Entretanto, como apontado por Rangel e Bagno (2006, p. 26): "nenhum dicionário, por mais exaustivo que se pretenda em sua cobertura e descrição, atinge efetivamente a completude. Mal é editado e publicado, e já o léxico mudou, aqui ou ali." Além da mudança lexical, comum a qualquer língua viva, os dicionários podem ser estruturados de diferentes formas, a depender do público-alvo, objetivo, filiação teórica, etc. É por isso que, embora seja um dicionário referência no Brasil e em Portugal, o dicionário de Aurélio Buarque de Holanda Ferreira, assim como outros, foi alvo de algumas críticas.

Biderman (1984, p. 07) elenca algumas e trata até mesmo da quantidade de entradas na obra:

O Aurélio acolheu muitas palavras raras, um grande número de regionalismos, de vocábulos desusados ou obsoletos, de termos exclusivamente literários, um vasto acervo de termos técnicos e científicos, o que inchou demais a sua nomenclatura. (Biderman, 1984, p. 7)

No prefácio da primeira edição, Aurélio Buarque de Holanda Ferreira, o autor da obra, aponta que o dicionário não contém apenas a língua dos escritores, mas também a encontrada nos mais diversos gêneros, como a língua dos jornais e revistas, do teatro, do rádio e televisão, o falar do povo, os linguajares diversos - regionais, jocosos, depreciativos, profissionais, giriescos. O autor lembra também dos escritores de letras de samba, marchas, canções, dos comentaristas políticos, econômicos e dos repórteres e noticiaristas, totalizando 770 autores.

É sobre as fontes do Aurélio (1975) uma das críticas de Biderman (1984). A esse respeito, ela diz que o corpus é "relativamente homogêneo", não abarcando, desse modo, a diversidade de gêneros prometida no prefácio da obra. Além disso, afirma que,

\footnotetext{
${ }^{7}$ Ao nos referirmos a essa versão de 1975 citaremos Aurélio (1975).
} 
embora a quantidade de autores apresentados no dicionário seja significativa, "as abonações são pouco frequentes".

A crítica mais severa parece ser quanto ao modo como o dicionarista realizou as definições dos verbetes. Segundo Biderman (1984, p. 10): “o recurso de definir por sinônimos, muito realizado por Aurélio, não é um bom método", “[a] forma do verbete [...] é criticável em numerosíssimos casos", todos listados em seu texto.

A autora ainda discute a ordem das acepções de uma palavra polissêmica, afirmando que: “[...] o dicionário dispõe inadequadamente a sequência não ficando muito claro o critério de distribuição dos sentidos registrados" (1984, p. 10). De fato, não há nenhuma explicação no prefácio sobre como as acepções foram ordenadas.

Ao categorizar tipologicamente as obras lexicográficas, Biderman (1984, p. 11) coloca o Aurélio (1975) como sendo um dicionário padrão da língua. As críticas são resultado das diversas possibilidades que cercam o fazer lexicográfico, portanto, é necessário reconhecer que, embora seja passível de críticas, trata-se de uma obra de referência e, ainda que tenha sido feita com base na variante brasileira do português, também passou a ser bastante utilizada em Portugal, como apontado por Krieger et al. (2006, p. 183).

O sucesso do dicionário é inegável, o que explica ter chegado, em 2010, à sua quinta edição revista e atualizada por Marina Baird Ferreira, sendo essa, a utilizada neste trabalho. Essa edição traz uma grande quantidade de informações: pronúncia, índice, categoria gramatical, etimologia, rubrica, remissivas, transcrição fonética, regência, bem como exemplos e abonações.

\section{A escolha dos verbos}

Como já mencionamos, os verbos a serem analisados neste trabalho são cinco, a saber: agarrar, apanhar, catar, pegar e tomar. A escolha por esses verbos se justifica pelo fato de percebermos, intuitivamente, que eles pertencem a um mesmo campo semântico, o de tomar posse de um objeto para si.

A fim de cumprir o primeiro objetivo deste trabalho, consultamos o Aurélio (2010), e com base nas acepções trazidas para esses verbos, delimitamos uma que 
acreditamos ser compartilhada por todos, a de "apossar-se de algo"8. Neste trabalho, consideraremos apenas os dados em que se trate da posse de um objeto concreto.

Desse modo, na próxima seção, discorreremos brevemente sobre a questão da sinonímia e mostraremos as informações apresentadas em Houaiss (2008) no que tange à relação de sinonímia entre os verbos agarrar, apanhar, catar, pegar e tomar.

\subsection{A sinonímia}

Se para um leigo, duas palavras podem ser empregadas com sentidos idênticos em determinado contexto, os estudiosos da sinonímia entendem que não há sinônimos perfeitos, portanto, nenhuma palavra pode substituir outra sem que haja alguma perda de sentido. Em meio a isso, muitos estudos têm sido desenvolvidos em torno da sinonímia, tais como: Vereza (2000) e Margotti (2003).

Ilari (2011, p. 169) afirma que: “Os sinônimos são palavras de sentido próximo, que se prestam, ocasionalmente, para descrever as mesmas coisas e as mesmas situações". Entretanto, o autor ressalta que não existem sinônimos perfeitos, uma vez que a escolha entre dois sinônimos depende de alguns fatores, a saber: a fidelidade às características regionais da fala; o grau de formalismo da fala; a preocupação de ressaltar as diferenças de sentido, as diferenças entre os objetos de que se fala e certos aspectos de forma ou função (2011, p. 169).

Embora tenhamos conhecimento da inexistência de sinônimos perfeitos, tal como discutido e justificado em Ilari (2011), verificamos, com base na análise das acepções dos verbos agarrar, apanhar, catar, pegar e tomar no Aurélio (2010), que a ação de tomar posse de um objeto é comum a todos e que, portanto, quando ocorrem em contextos linguísticos codificando essa ação, eles podem ser intercambiáveis.

Em uma consulta ao Dicionário Houaiss: sinônimos e antônimos $(2008)^{9}$, de Antônio Houaiss, verificamos que, nessa obra, não há um contexto no qual todos os verbos agarrar, apanhar, catar, pegar e tomar possam ocorrer. O autor mostra

\footnotetext{
${ }^{8}$ Essa acepção, assim nomeada, foi criada por nós, por concluirmos, com base nas acepções que o Aurélio (2010) traz aos verbos agarrar, apanhar, catar, pegar e tomar, que essa seria a acepção comum entre todos eles

9 Doravante, nos referiremos ao Dicionário Houaiss: sinônimos e antônimos (2008), apenas por Houaiss (2008).
} 
contextos bem específicos nos quais um ou outro verbo pode aparecer como sinônimos, mas um contexto em que todos sejam possíveis não é mostrado na obra.

Desse modo, separamos, a seguir, as acepções em que os verbos, de acordo com o Houaiss (2008), podem ser substituídos uns pelos outros:

agarrar: (p. 35)

$[\ldots]$ 5. segurar $^{10}:$ apanhar $^{11}$, pegar $[\ldots]$

6. fig. usurpar: furtar, roubar, tomar

apanhar: (p. 67)

v. 1. agarrar: aprisionar, capturar, pegar, prender $<$ apanhar os fugitivos ${ }^{12}>[\ldots]$

2. atingir: alcançar, tomar $<$ a tempestade apanhou o barco no mar $>[\ldots]$

3. catar: (re)colher, juntar, pegar <apanhar frutas $>$

4. captar: aproveitar, [...], pegar <apanhar água da chuva>

5. contrair: adquirir, pegar $<$ apanhar gripe $>[\ldots]$

8. embarcar: pegar, tomar $<$ apanhar o trem> $[\ldots]$

10. roubar: furtar, tomar, usurpar <apanhar objetos alheios $>$

11. imitar: copiar, pegar, reproduzir $>$ apanhar o sotaque $>$

13. segurar: amparar, pegar $<$ apanhar a criança no colo $>[\ldots]$

14. tomar: pegar $<$ apanhar chuva $>$

catar: (p. 159)

[...] 5. recolher: apanhar, juntar, pegar $<$ catar gravetos $>$

pegar: (p. 618-619)

[...] 2. aceitar: assumir, combinar, [...], tomar $<$ pegar um serviço $>[\ldots]$

5. apanhar: agarrar, prender, segurar $<$ pegar pelo pé>

11. buscar: apanhar, levar, trazer <vou pegar a chave $>$

${ }^{10}$ Os termos em itálico representam as palavras-chave de cada acepção.

${ }^{11}$ As palavras que aparecem sublinhadas foram destacadas pelas autoras deste artigo para mostrar em cada acepção a presença dos verbos que vamos analisar neste trabalho.

12 Entre colchetes angulares têm-se os exemplos apresentados na obra de Houaiss (2008) para as acepções. 
19. embarcar: apanhar, tomar $<$ pegou um avião $>$

24. pescar: apanhar, caçar <pegou muitos peixes>

27. receber: apanhar, ser atingido, tomar $<$ gostava de pegar sol $>$

tomar: (p. 809)

v. 1. aceitar: pegar, receber <tomou o donativo das mãos do benfeitor $>$ [...];

4. agarrar: aguentar, segurar, [...] <tomou-lhe a mão $><$ tomar as rédeas da situação $>[\ldots]$;

6. apanhar: alcançar, pegar $<$ tomar chuva $>[\ldots]$;

16. embarcar: apanhar, pegar $<$ tomar o ônibus errado $>[\ldots]$;

18. empunhar: pegar, segurar <tomar da caneta para escrever $>[\ldots]$;

20. expor-se: apanhar, pegar $<$ tomar sol $>[\ldots]$;

21. flagrar: apanhar, pegar, $[. .]<$. a polícia tomou-o com a muamba na mão> $[\ldots]$

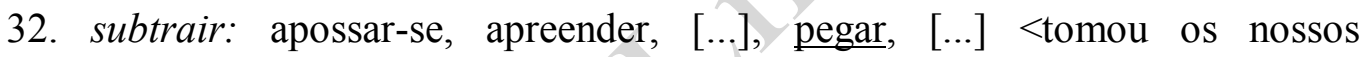
brinquedos $>[\ldots]$;

34. utilizar: pegar, recorrer, usar [...] <tomou a melhor montaria $>$

É importante ressaltar que as acepções acima foram retiradas do Houaiss (2008) e que nós separamos todas ${ }^{13}$ as acepções em que os cinco verbos podem ser substituídos entre si, mesmo que a acepção não constitua o campo semântico "apossar-se de algo", foco da nossa análise. Isso porque, apesar de termos como objetivo mostrar que os cinco verbos em análise têm uma acepção comum, o dicionário revela que eles podem ser utilizados uns pelos outros com outras significações, além da de tomar posse.

Vê-se nas informações descritas acima que, conforme dito anteriormente, no Houaiss (2008) não há uma acepção na qual a ocorrência de todos os verbos seja possível. Tomemos como exemplo as informações acerca do verbo agarrar. Sobre ele, o dicionário mostra que apenas os verbos apanhar e pegar são seus sinônimos quando ele codifica a ação de segurar. Mostra ainda que o verbo agarrar é sinônimo do verbo

${ }^{13}$ Como a nossa intenção não é analisar a polissemia dos verbos, não discutiremos as acepções que retiramos do Houaiss (2008). 
tomar somente quando tem o sentido de usurpar. O mesmo é feito com os outros verbos, o autor apresenta quais são seus sinônimos e o contexto nos quais eles o são. Desse modo, fica claro que, em outros contextos, além daqueles especificados, os verbos não podem ser considerados sinônimos.

No entanto, a partir da análise das acepções do Aurélio (2010) para esses verbos, chegamos à conclusão de que a ação de tomar posse de um objeto é compartilhada por todos os cinco verbos, por isso, nesse contexto linguístico, entendemos que eles podem ser considerados sinônimos.

\section{Metodologia}

A primeira exigência metodológica imposta por essa pesquisa foi a delimitação do objeto de estudo a ser tratado sob o ponto de vista da Lexicografia. Desse modo, optamos por analisar os verbos agarrar, apanhar, catar, pegar e tomar, pois são semanticamente próximos.

Para cumprir os objetivos estabelecidos, realizamos, inicialmente, uma consulta a dois dicionários da Língua Portuguesa de grande relevância aos estudos lexicográficos, a saber: o Dicionário Houaiss: sinônimos e antônimos (2008) e o Dicionário Aurélio da Língua Portuguesa (2010).

No primeiro, buscamos por cada um dos verbos em análise a fim de verificar seus sinônimos. Acreditávamos que encontraríamos, nesse dicionário, uma acepção comum a todos os verbos, porém, conforme apresentado na seção 3.1. A Sinonímia, Houaiss (2008) mostra que os verbos agarrar, apanhar, catar, pegar e tomar podem ser sinônimos, mas não em um único contexto como propomos neste trabalho.

Por não termos conseguido confirmar, com base no Houaiss (2008), se há uma acepção comum a todos os verbos, recorremos ao Aurélio (2010). Após analisarmos as acepções que esse dicionário traz para os verbos, identificamos um sentido comum a todos, por meio do qual codificam a ação de tomar posse de um objeto para si. Desse modo, determinamos que a acepção comum aos verbos é a de "apossar-se de algo".

Por outro lado, também verificamos, nessa mesma obra, que, embora compartilhem essa acepção, cada um dos cinco verbos detém acepções particulares, o 
que permite que eles sejam utilizados em contextos específicos, nos quais o uso de qualquer outro verbo parece ser bloqueado.

Para comprovar isso, recorremos a um corpus que dispõe de dados das modalidades escrita e falada do Português a fim de identificar o contexto no qual a ocorrência de todos os cinco verbos é possível sem que haja mudança de significado da frase e os contextos específicos a cada um. Assim, utilizamos o Corpus do Português, um corpus disponível online para uso público no site www.corpusdoportugues.org, a partir do qual realizamos a coleta de dados.

O Corpus do Português é constituído por mais de 45 milhões de palavras, distribuídas em quase 57 mil textos do português brasileiro e europeu, dos séculos XIV ao XX. Além da busca de dados, o corpus permite realizar a comparação de frequência e de distribuição de palavras, frases e construções gramaticais entre séculos, entre variedades do português (PB e PE) e entre registros (oral, ficção, jornalístico e acadêmico). Neste momento, entretanto, canalizamos a discussão para os dados do português brasileiro do século $\mathrm{XX}$, tanto dos textos orais, quanto dos jornalísticos, ficcionais e acadêmicos. A página digital do Corpus do Português disponibiliza uma ferramenta de busca própria, a partir da qual buscamos pelas ocorrências dos verbos em análise.

Apresentamos abaixo, os contextos comuns e os particulares de cada um dos verbos investigados, bem como sua análise.

\section{Análise}

Da análise feita a partir das acepções que o Aurélio (2010) traz para os verbos agarrar, apanhar, catar, pegar e tomar, delimitamos uma que se aplica a todos eles, a qual denominamos "apossar-se de algo". Além disso, ainda com base nas acepções que o Aurélio (2010) traz para esses verbos, delimitamos uma acepção que consideramos ser específica de cada verbo, chegando, portanto, às acepções apresentadas na tabela 1: 
Tabela 1 - Acepções dos verbos agarrar, apanhar, catar, pegar e tomar

\begin{tabular}{l|c|c|c|c|c|c}
\hline & $\begin{array}{c}\text { Prender } \\
\text { com garra }\end{array}$ & $\begin{array}{c}\text { Colher; } \\
\text { recolher }\end{array}$ & $\begin{array}{c}\text { Escolher; } \\
\text { selecionar }\end{array}$ & Segurar & Tirar & $\begin{array}{c}\text { Apossar-se } \\
\text { de algo }\end{array}$ \\
\hline Agarrar & $\mathrm{X}$ & & & & & $\mathrm{X}$ \\
\hline Apanhar & & $\mathrm{X}$ & & & & $\mathrm{X}$ \\
\hline Catar & & & $\mathrm{X}$ & & & $\mathrm{X}$ \\
\hline Pegar & & & & $\mathrm{X}$ & & $\mathrm{X}$ \\
\hline Tomar & & & & & $\mathrm{X}$ & $\mathrm{X}$ \\
\hline
\end{tabular}

Inicialmente, na seção 5.1. Acepção "apossar-se de algo" trataremos dos casos em que todos os verbos compartilham a acepção que aparece na última coluna: “apossar-se de algo" e na seção 5.2. Acepções particulares dos verbos apresentaremos os dados coletados do Corpus do Português que ilustram as acepções particulares que determinamos na tabela 1 para cada um dos verbos agarrar, apanhar, catar, pegar e tomar.

\subsection{Acepção "apossar-se de algo"}

\section{Verbo agarrar}

(1) "E aquela mão agarrava a boneca assim. Então você via os olhos da boneca pingando água. Um choro terrível. Ele atirava ela sem piedade, botava o pé em cima e o pai então dizia assim: Oh! Meu filho não faça uma coisa dessa." (Texto oral)

(2) "Não podia haver dúvida a respeito. Sorveu o seu uísque com calma, sem agarrar o copo nos dedos convulsos, acendeu um cigarro, soprou a fumaça para o teto. Estava distendido, afrouxado. - Que malandraço, o Pedroca." (Texto ficcional - Título: $A$ Madona de Cedro de António Callado)

(3) "Este movimento pelas árvores é facilitado pois, assim como os macacos, o dedão do pé é bem separado dos outros e trabalha como se fosse o polegar da mão dos humanos. Com a cauda, podem se pendurar nos galhos e agarrar frutas. São animais de hábitos noturnos e passam o dia descansando em fendas nas rochas, buracos nos troncos, sob pilhas de galhos cortados, ou em covas cavadas por eles mesmos." (Texto acadêmico - Título: Gambá) 
(4) "A cada resposta correta em o ${ }^{14}$ caso, alguém teria que dizer Pomodoro, a dupla ganha dez segundos de consumo grátis em o supermercado-estúdio. Em o segundo, com um carrinho de compras, um representante de cada dupla corre alucinado por o supermercado agarrando produtos." (Texto jornalístico - Título: FOLHA: 3346: SEC:clt-soc)

\section{Verbo apanhar}

(5) "Perguntei à sobrinha, d. Letícia, o que era aquilo, ela disse que eram 'coisas do Bandeira' e eu lhe faria um favor em levá-las. Desci, apanhei na mala do carro umas sacas das Casas da Banha, enchi de papéis e hoje temos 1,3 mil documentos do Bandeira." (Texto oral - Título: Plínio Doyle)

(6) "[...] acontece que com o sol muito forte o material resinoso - éh: descolava e a placa por si mesmo enrolava e o furo permanecia e chovia () em cima - e isso aí foi o problema aqui durante quase uns três meses - até um belo dia que surgiu o ovo de Colombo - é simplesmente a gente não tinha mais o que fazer aqui e apanhamos um tubo de araldite - despejamos um pouco em cima misturamos em cima da calha mesmo e até hoje ela nunca mais éh vasou [...]" (Texto oral - Título: Linguagem falada: Recife: 4)

(7) "Este é o pressuposto necessário à sua campanha eleitoral, cuja fórmula é conhecida. Anuncia o caos para apresentar-se como salvador. Solta o foguete e corre para apanhar a vareta. Procura desmoralizar Jaime Lerner e depois pede para substituí-lo.” (Texto jornalístico - Título: Fábio Campana)

(8) "Foi tudo tão rápido, tão confuso, que mal consigo organizar as lembranças na memória, sem saber o que veio antes, durante ou depois. Eu havia voltado para apanhar algumas fotos, letras de música, talvez para conversar um pouco mais com ela, não lembro ao certo." (Texto ficcional - Título: Santa Sofia de Angela Abreu)

\section{Verbo catar}

(9) "Eu queria na capa uma foto da mamãe da forma que eu me lembrava, e não achava nenhuma. Saí catando uns jornais antigos e achei a foto, levei pra Cid, o cara, que agora não me recordo o nome, desenhou, feito fotografia, ficou maravilhoso." (Texto oral - Título: Claudia Telles)

(10) "Mas para quê, meu Espírito Santo? Engoliu um soluço e sentiu vergonha. Nesse instante já estava em frente do Instituto Disciplinar. Abaixou-se. Catou uma pedra. Pá! $\mathrm{Na}$ árvore. Bem no meio do tronco. Catou outra. Pá! No cachorro. Bem no meio da

\footnotetext{
${ }^{14}$ A forma em o, presente no dado (4), embora cause estranhamento, é a forma apresentada no corpus, por isso, manteremos aqui do mesmo modo.
} 
barriga." (Texto ficcional - Título: Laranja-da-China de Antônio Castilho de Alcântara Machado D'Oliveira)

(11) "Devia estar dormindo. Fui desligar a vitrola, mas ele pediu, sem tirar o antebraço do rosto: - Bota aquela música do Napoleão. Eu sabia que era o Concerto número 5, para piano e orquestra, de Beethoven, música preferida dele. Enquanto catava o disco na estante, dei graças a tudo aquilo: afinal, eu deixara de pensar na vaca. Estava pessimamente informado." (Texto ficcional - Título: O piano e a orquestra de Carlos Heitor Cony)

(12) "Eu morava em favela, casa de dois cômodos. Você cata um dinheiro, vai fazer show, quer o quê? Quer se jogar. Eu pensava o quê? Em dar uma casa pra minha mãe." (Texto oral - Título: Mano Brown)

\section{Verbo pegar}

(13) "Você não transforma um torneiro mecânico num microempresário se ele não tiver as condições inatas da atividade empresarial, não adianta chegar e falar: 'Pode pegar seu torno aqui da firma e leva para sua casa' e vai ter um microeempresário, se não tiver noções do que fazer com aquele torno, qual é o mercado, onde conquistar, como administrar.” (Texto oral - Título: Marcel Domingos Solimeo)

(14) "Que se há de fazer? - completei. - Me dá o telefone delas. Ele afastou uma pilha de laudas, pegou uma agenda. Havia mais papéis soltos dentro dela do que todas as páginas juntas.” (Texto ficcional - Título: Santa Sofia de Angela Abreu)

(15) "E olha que o método de venda via Internet não envolve uma das formas mais importantes que é a compra por impulso, aquele de ver, pegar e levar." (Texto oral Título: Edgar Franco)

(16) "Além de passar frio, perdeu o compromisso seguinte. Ontem, depois do almoço com 470 empresários canadenses no hotel Four Seasons, em Toronto, ela pegou o casaco errado. A noite, já em Montreal, ainda tentava encontrar o dono do casaco e recuperar o seu.” (Texto jornalístico - Título: Por Cristina Lôbo)

(17) "Eu lembro que na época a gente entrava nas redações pra distribuir o jornal e, no início, as pessoas não queriam pegar porque achavam que era o jornal do Sindicato. Depois elas viram que não era.” (Texto oral - Título: Alberto Jacob Filho)

\section{Verbo tomar}

(18) "[...] por sorte Não mexeram na nossa casa - nessa ocasião meu pai estava morando em Piracicaba - quando veio a revolução ele disse 'se for pra fazer a revolução vou fazer a revolução na minha - casa na minha fazenda' - tomou o carro foi - para a fazenda - mas por sorte a revolução foi - tão eficiente e tão rápida que quando ele 
chegou lá os agitadores já tinham todos desaparecidos [...]" (Texto oral - Título: orBrLF-SP-3:208)

(19) "No dia seguinte, quando o guarda que nos veio abrir a porta, deu-me uma vassoura e um pano com que eu ajudasse a ele e outros a baldear o quarto-forte e a varanda, não fiz nenhum movimento de repulsa. Tomei os dois objetos e cumpri docilmente o mandato. O que me aborreceu, porém, foi a minha falta de forças e hábito de abaixar-me, para realizar tão útil serviço." (Texto ficcional - Título: O Cemitério dos Vivos de Lima Barreto)

(20) "Senti muito a falta de minha mulher e toda a minha culpa, puramente moral e de consciência, subiu-me à mente. Pensei. Não. Não. Era um crime. Tomei a vassoura de jardim, e foi com toda a decisão que, calçado com uns chinelos encardidos que haviam sido de outros, com umas calças pelos tornozelos, em mangas de camisa, que fui varrer o jardim, mais mal vestido que um pobre gari." (Texto ficcional - Título: O Cemitério dos Vivos de Lima Barreto)

(21) “O Dr. Siqueira Rolim escutou, vermelho de indignação. 'Es-te farsante, este urubu malandro, este degenerado poderá pôr tudo a perder' Tomou o telefone e ligou, ele mesmo, diretamente, para o delegado Pulmann." (Texto ficcional - Título: A Greve dos desempregados de Luiz Beltrão)

Os dados apresentados acima, de (1) a (21), mostram que quando codificam a ação de "apossar-se de algo", os verbos agarrar, apanhar, catar, pegar e tomar realmente podem ser intercambiáveis entre si, ao contrário do que é mostrado em Houaiss (2008), obra em que não encontramos referência a um contexto comum a todos esses verbos do português.

Embora tenhamos mostrado, a partir dos dados coletados do Corpus do Português, a intercambialidade dos verbos quando codificam a ação de "apossar-se de algo", acreditamos que a escolha do falante por um ou outro verbo parece ter implicações de ordem estilística, mas não semântica.

\subsection{Acepções particulares dos verbos}

Os verbos agarrar, apanhar, catar, pegar e tomar possuem acepções particulares que os diferenciam entre si, todas mostradas na tabela 1. Por isso, nesses contextos específicos, a substituição entre eles parece não ser possível. Desse modo, faz-se necessário ilustrar esses casos. 


\section{Verbo agarrar: acepção "prender com garra"}

(22) "Isabel teve um gesto de menino a dar de ombros e o olhou com expressão canalha: - Deixe-me em paz. Não estou para morrer de aborrecimento na casa de meu tio. Pelo menos, isto aqui tem mais animação. Leonel ficou cada vez mais trémulo e, agarrandoa com violência, disse: - Tu vais comigo, ainda que precises levar uma surra." (Texto ficcional - Título: O Galo de Ouro, de Rachel de Queiroz)

A acepção mais específica do verbo agarrar em relação aos outros do mesmo campo semântico é o de "prender com garra". Assim, em (22) é possível perceber que essa acepção do verbo implica um sentido mais intenso ao ato de prender. Não se trata apenas de prender a mulher, forçando-a a ir embora com ele, mas sim de prendê-la com uma força tão intensa que tal atitude atinge um grau de violência.

(23) Delira à meia voz, tem o seu quarto muito limpo pelas suas mãos, cuida dos gatos, das plantas, chegou até a plantar batatas e colhê-las, gosta de agarrar camundongos, esfolá-los e conservar as peles. (Texto ficcional - Título: O Cemitério dos Vivos, de Lima Barreto)

(24) "Ficara-lhe no ouvido toda a censura dela, e houve então nele um ímpeto de agarrar Mila e de beijá-la mesmo ali, diante dos olhos castos e pudibundos da velha." (Texto ficcional - Título: A Falência, de Júlia Lopes de Almeida)

Em (23), do mesmo modo que o exemplo (22), percebe-se que a ação de agarrar implica um movimento bruto, sem que haja preocupação se tal ato irá ou não machucar o animal. Em (24), por outro lado, embora o verbo agarrar implique a noção de "prender com garra", não é possível interpretar esse dado como codificando um ato violento, ríspido. Nesse caso, o verbo agarrar implica a ação de abraçar a moça fortemente, de modo a prendê-la junto ao rapaz.

\section{Verbo apanhar: acepção "colher, recolher"}

(25) "Ignorando tratar-se de um ardiloso truque elaborado por Zeus para atraí-la para os braços de seu irmão, a inocente jovem se aproximou, inclinando-se para apanhar flor tão singela. Subitamente, a terra abriu-se aos seus pés e de suas entranhas surgiu Hades dentro de um carro." (Texto acadêmico: Perséfone) 
O Aurélio (2010) traz, dentre outras, a acepção “colher, recolher" para o verbo apanhar. Essa nos pareceu ser a acepção mais específica desse verbo, a que o diferencia dos demais.

Verificamos no Corpus do Português que o verbo apanhar, usado num contexto no qual codifica a ação de "colher, recolher", implica um ato de pegar algo do chão levantando-o, recolhendo-o. Isso se confirma em (25), no qual há uma descrição do ato de uma jovem que pega uma flor do chão, levantando-a.

\section{Verbo catar: acepção "escolher, selecionar"}

(26) "Geralmente, Rotundo ia até uma passagem de pedestre para atravessar a rua; naquela manhã, porém, o movimento de veículos estava reduzido. ao alcançar o Parque, observou que a Prefeitura deveria afinal ter tomado em conta as reclamações da Associação: havia trabalhadores em ação por todas as alamedas. Jardineiros podavam árvores, revolviam canteiros, acertavam a grama, catavam ervas daninhas, enquanto garis restelavam e recolhiam em um carrinho os resíduos e as folhas caídas." (Texto fíccional - Título: A Greve dos Desempregados, de Luiz Beltrão)

(27) "Lá estava a choupana, mas lá não estava o velho. Saltei do carro. A porta estava aberta, entrei e examinei o cômodo único onde o velho comia, dormia e, entre uma e outra função, vivia. Já ia me afastando da choupana quando vi uma mulher que catava feijão entre os pés de milho." (Texto ficcional - Título: O Piano e a Orquestra, de Carlos Heitor Cony)

Os dados (26) e (27), que foram extraídos de textos ficcionais, exemplificam uma das acepções básicas do verbo catar, que é a de escolher, selecionar. Em (26), para eliminar as plantas que podem prejudicar o crescimento do jardim e, assim, podar o espaço, o jardineiro precisa selecionar as plantas que precisam ser retiradas do local. Já em (27), a tarefa de catar feijão, que é bastante comum na vida de quem cozinha, também implica seleção, uma vez que o catador procura dentre os grãos aqueles que não servem para o consumo e os elimina.

Verbo pegar: acepção "segurar"

(28) "Está bem - concordou Masakado, embora não conseguisse se concentrar em coisa alguma. 
- Por favor.. pegue esta espada e fique em posição de ataque - disse Yasumori.." - Peço-lhe que atue com decisão, sem receio de me ferir. (Texto ficcional Título: A Sala do Jogo, de Eduardo Alves da Costa)

Em (28), temos um exemplo de uma das acepções básicas do verbo pegar: "segurar". Esse dado, extraído de um texto ficcional do Corpus do Português, mostra que o agente da ação deverá segurar a espada nas mãos até o momento em que decidir dar o golpe com a espada.

Verbo tomar: acepção "tirar"

(29) "Nunca soube a razão, mas sei que provocou uma briga na hora do almoço. Antes que outros entrassem no meio, dei-lhe um safanão e lhe tomei o garfo com que ameaçava o olho de Orestes. Caiu de mau jeito e ainda levou uns bons cascudos." (Texto fíccional - Título: O Braço direito, de Otto Lara Resende)

No exemplo acima, o verbo tomar aparece em uma de suas acepções básicas, a de "tirar". Em (29), o verbo tomar indica uma ação abrupta do sujeito que pega o garfo da mão de alguém. Essa leitura é favorecida, pois, o ambiente onde a ação ocorre está cercado por briga e discórdia.

Os dados de (22) a (29) ilustram as acepções específicas que, após consulta e análise do Aurélio (2010), determinamos para os verbos agarrar, apanhar, catar, pegar e tomar. Com isso, confirmamos que, em certos contextos linguísticos, esses verbos são usados com um sentido diferente da acepção "apossar-se de algo" e que essa diferença de significado pode explicar a existência dos cinco verbos no português.

\section{Conclusão}

A apresentação dos aspectos relacionados à produção lexicográfica no Brasil e sua relação com a linguística de corpus nos levou a observar a gama de estudos já realizados e os que ainda podem surgir na área. Este artigo demonstra apenas uma das possibilidades de se realizar uma análise no âmbito da Lexicografia. Sabemos, portanto, da imensidão de assuntos que ainda podem ser explorados, mas esperamos ter colaborado com as discussões acerca das acepções verbais, especialmente, no que se 
refere aos verbos agarrar, apanhar, catar, pegar e tomar, que foram o nosso objeto de estudo. Além disso, esperamos ter colaborado com a difusão do debate sobre a importância e a necessidade de se utilizar corpus no fazer lexicográfico.

No que tange mais especificamente aos verbos investigados, destacamos a questão da sinonímia. Houaiss (2008) apresenta os contextos nos quais os verbos podem ser substituídos uns pelos outros, porém, nesse dicionário não há evidência de que todos os verbos possam ser sinônimos em um mesmo contexto.

Mostramos, com este trabalho, que, embora não tenhamos encontrado evidências em Houaiss (2008) de que há uma acepção comum a todos os verbos, verificamos, a partir da análise dos dados coletados do Corpus do Português, que os cinco verbos codificam a ação de tomar posse de um objeto para si. Desse modo, concluímos que eles têm uma acepção em comum, tal como hipotetizávamos, a de "apossar-se de algo".

Por outro lado, apresentamos a acepção específica que cada verbo possui e que melhor o identifica dentre os demais. Com base no Aurélio (2010), delimitamos que, para o verbo agarrar, a acepção mais específica é "prender com garra", para o verbo apanhar é "colher, recolher", para o verbo catar é "escolher, selecionar", para o verbo pegar é "segurar" e para o verbo tomar é "tirar".

Desse modo, cada verbo que codifica a ação de tomar posse de um objeto para si apresenta, também, acepções particulares, o que parece explicar a coexistência de todos no português e o uso específico de cada um. Como sabemos, as línguas naturais são regidas pelo princípio da economia da língua e, por isso, conforme Correia (1995), tendem para a simplificação, que decorre da eliminação de informações redundantes. Ainda que compartilhem uma mesma acepção, a coexistência desses verbos num mesmo recorte sincrônico se explica pelo fato de cada um deles ocorrer em contextos particulares.

Por fim, sinalizamos a importância da utilização do corpus para a realização deste trabalho, uma vez que somente com os dados coletados do Corpus do Português foi possível comprovar empiricamente que os verbos agarrar, apanhar, catar, pegar e tomar têm uma acepção em comum, a de "apossar-se de algo". 


\section{Referências}

BARroso, G.; LIMA, H. Pequeno Dicionário Brasileiro da Língua Portuguesa. 1. Ed. Rio de Janeiro, São Paulo: Civilização Brasileira, 1938.

BÉJOINT, H. Modern lexicography an introduction. Nova York: Oxford, 2000. In: WELKER, H. A. Dicionários: uma pequena introdução à Lexicografia. Brasília: Thesaurus, 2005.

BIDERMAN, M. T. C. A ciência da Lexicografia. Alfa, São Paulo, 28 (supl.): 1-26, 1984.

Dicionário e Léxico do Português Brasileiro. 2001.

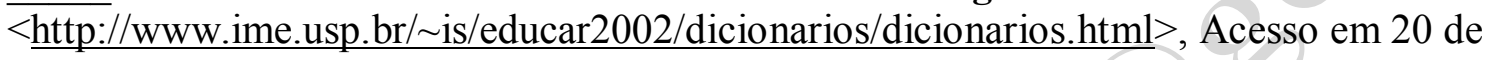
janeiro de 2012.

BLUTEAU, R. Vocabulario Portuguez e Latino. Vol. 1. 10 volumes. Coimbra: Colégio das Artes, $1712-1728$.

CORREIA, M. O léxico na economia da língua. Ciência da Informação - Vol. 24, número 3, 1995.

FERREIRA, A. B. de H. Dicionário Aurélio da Língua Portuguesa. Coordenação de Marina Baird Ferreira. Margarida dos Anjos. - 5. ed. Curitiba: Positivo, 2010. 1975.

Novo Dicionário da Língua Portuguesa. Rio de Janeiro: Nova Fronteira,

FREIRE, L. Grande e Novíssimo dicionário da língua portuguesa. Rio de Janeiro: A Noite, 1939 - 1944.

FROMM, G. O uso de corpora na análise linguística. Revista Factus, São Paulo, v. 1, p. 69-76, 2003.

HOUAISS, A. Dicionário Houaiss: sinônimos e antônimos. 2. ed. São Paulo: Publifolha, 2008.

ILARI, R. Introdução ao estudo do léxico - brincando com as palavras. 5. ed. São Paulo: Contexto, 2011.

KRIEGER, M. da G.; MÜller, A. F.; GARCIA, A. R. da R.; BATISTA, R. P. O século $\mathrm{XX}$, cenário dos dicionários fundadores da lexicografia brasileira: relações com a identidade do português do Brasil. Alfa, São Paulo, 50 (2): 173 - 187, 2006.

MARGOTTI, F. W. Sinonímia e paráfrase: algumas considerações a partir de dados do atlas linguístico-etnográfico da região sul - ALERS. In: Linguagem em (Dis)curso, Tubarão, v. 3, n. 2, jan./jun. 2003, p. 27-46. 
MÜller, A. F.; BATISTA, R. P.; KRIEGER, M. da G. A Lexicografia brasileira do século XX: dicionários inaugurais e temáticas. Anais do XIII CNFL. Rio de Janeiro: CiFEFiL, 2009.

NASCENTES, A. Dicionário da língua portuguesa. Rio de Janeiro: Academia Brasileira de Letras; Bloch, 1961-1967.

NUNES, J. H. Dicionários: história, leitura e produção. Conferência de encerramento do $8^{\circ}$ Encontro de Letras da Universidade Católica de Brasília, 2010.

RANGEL, E. de O.; BAGNO, M. Dicionários em sala de aula. Brasília: Ministério da Educação, Secretaria de Educação Básica, 2006.

SILVA, A. de M. Dicionario da Língua Portuguesa, composto pelo Padre D. Rafael Bluteau, reformado, e acrescentado por Antonio de Morais Silva natural do Rio de Janeiro. Lisboa: Officina de Simão Thaddeo Ferreira, 1789.

VEREZA, S. C. Contextualizando o léxico como objeto de estudo: considerações sobre sinonímia e referência. In: Delta, São Paulo, v. 16, n.1, 2000. Disponível online em: http://www.scielo.br/scielo.php?script $=$ sci arttext\&pid=S0102-

$\underline{44502000000100004 \& \operatorname{lng}=\mathrm{pt \& nrm}=\mathrm{iso}}$, Acesso em 22 de junho de 2012.

WELKER, H. A. Dicionários: uma pequena introdução à Lexicografia. Brasília: Thesaurus, 2005.

Artigo recebido em: 30.03.2012

Artigo aprovado em: 25.06.2012 